OPEN ACCESS

Edited by:

Guido Moll,

Charité-Universitätsmedizin Berlin,

Germany

Reviewed by:

Paschalis Ntolios,

Democritus University of Thrace,

Greece

Rebecca Lyn Toonkel,

Florida International University,

United States

*Correspondence:

Zai Wang

wzai_163pass@163.com

Huaping Dai

daihuaping@ccmu.edu.cn

${ }^{\dagger}$ These authors have contributed equally to this work and share first

authorship

Specialty section

This article was submitted to

Stem Cell Research,

a section of the journal

Frontiers in Cell and Developmental

Biology

Received: 09 December 2020

Accepted: 15 February 2021

Published: 09 March 2021

Citation:

Yang S, Liu P, Jiang Y, Wang Z,

Dai $H$ and Wang $C$ (2021) Therapeutic Applications of Mesenchymal Stem

Cells in Idiopathic Pulmonary Fibrosis.

Front. Cell Dev. Biol. 9:639657.

doi: 10.3389/fcell.2021.639657

\section{Therapeutic Applications of Mesenchymal Stem Cells in Idiopathic Pulmonary Fibrosis}

\author{
Shengnan Yang ${ }^{1,2,3,4,5,6 t}$, Peipei Liu ${ }^{1,7 t}$, Yale Jiang ${ }^{8}$, Zai Wang $^{9 *}$, Huaping Dai ${ }^{1,2,3,4,5 *}$ and \\ Chen Wang ${ }^{1,2,3,4,5,10}$
}

'Department of Pulmonary and Critical Care Medicine, Center of Respiratory Medicine, China-Japan Friendship Hospital, Beijing, China, ${ }^{2}$ National Center for Respiratory Medicine, Beijing, China, ${ }^{3}$ Institute of Respiratory Medicine, Chinese Academy of Medical Sciences, Beijing, China, ${ }^{4}$ National Clinical Research Center for Respiratory Diseases, Beijing, China, ${ }^{5}$ WHO Collaborating Centre for Tobacco Cessation and Respiratory Diseases Prevention, Beijing, China, ${ }^{6}$ Harbin Medical University, Harbin, China, ${ }^{7}$ Graduate School of Peking Union Medical College, Chinese Academy of Medical Sciences and Peking Union Medical College, Beijing, China, ${ }^{8}$ School of Medicine, Tsinghua University, Beijing, China, ${ }^{9}$ Institute of Clinical Medical Sciences, China-Japan Friendship Hospital, Beijing, China, ${ }^{10}$ Chinese Academy of Medical Sciences and Peking Union Medical College, Beijing, China

Idiopathic pulmonary fibrosis (IPF) is an interstitial disease of unknown etiology characterized by progressive pulmonary fibrosis. Pirfenidone and nintedanib are the only drugs that can prolong the time to disease progression, slow down the decline in lung function, and prolong survival. However, they do not offer a cure and are associated with tolerability issues. The pluripotency of mesenchymal stem cells (MSCs) and their ability to regulate immunity, inhibit inflammation, and promote epithelial tissue repair highlight the promise of MSC therapy for treating interstitial lung disease. However, optimal protocols are lacking for multi-parameter selection in MSC therapy. This review summarizes preclinical studies on MSC transplantation for the treatment of interstitial lung disease and clinical studies with known results. An analysis of relevant factors for the optimization of treatment plans is presented, including MSCs with different sources, administration routes and timing, dosages, frequencies, and pretreatments with MSCs. This review proposes an optimized plan for guiding the design of future clinical research to identify therapeutic options for this complex disease.

Keywords: mesenchymal stem cells, idiopathic pulmonary fibrosis, stem cell transplantation, interstitial lung disease, interstitial fibrosis

\section{IDIOPATHIC PULMONARY FIBROSIS AND MESENCHYMAL STEM CELL THERAPY}

Idiopathic pulmonary fibrosis (IPF) is a chronic and irreversible interstitial lung disease characterized by progressive pulmonary fibrosis (Raghu et al., 2018). In high-resolution CT scans, IPF presents with typical imaging features of interstitial pneumonia (UIP) as reticular and honeycomb opacities, mainly distributed in subpleural and basal regions, accompanied by traction bronchiectasis. Pathologically, UIP lung tissue exhibits heterogeneous interstitial fibrosis, structural deformation, and fibroblast foci (Martinez and Flaherty, 2017). Disease prognosis is poor, with an average life expectancy of 3-5 years after diagnosis if untreated (Lederer and Martinez, 2018; Raghu et al., 2018) and a mortality rate exceeding that of many malignancies (Tzouvelekis et al., 2015; Karampitsakos et al., 2017). 
Over the past two decades, significant progress has been made in understanding the pathogenesis of IPF. In genetically susceptible aging individuals, recurrent environmental and/or repetitive alveolar epithelial micro-injury has been recognized as the trigger of disordered repair. Dysfunction of the alveolar epithelium is considered a key step in the initiation of IPF disease. Many factors that might underlie the dysfunction of epithelial cells in IPF have been proposed, including telomere shortening, aberrant mitochondrial bioenergetics, and increased endoplasmic reticulum stress induced by the unfolded protein response (UPR) (Lawson et al., 2011; Naikawadi et al., 2016). A relevant consequence of this is the production of profibrotic mediators, such as transforming growth factor-beta 1 (TGF- $\beta 1$ ), platelet-derived growth factor (PDGF); chemokine $\mathrm{C}-\mathrm{C}$ motif ligand 2 (CCL2); and $\mathrm{C}-\mathrm{X}-\mathrm{C}$ motif chemokine 12 (CXCL12) (Sgalla et al., 2018). TGF- $\beta 1$ is a powerful pro-fibrotic mediator that promotes epithelial cell apoptosis, epithelial-mesenchymal transition, and the production of other profibrotic mediators, such as vascular endothelial growth factor (VEGF), connective tissue growth factor (CTGF), and other pro-angiogenic mediators, forming a positive feedback loop (Grimminger et al., 2015). Dysregulated epithelial-fibroblast cross-talk promotes myofibroblast accumulation and excessive matrix deposition, which lead to continuous tissue remodeling and structural deformations (Barratt et al., 2018; Ballester et al., 2019). In addition, immune dysfunction is also one of the drivers of IPF (Shenderov et al., 2021). CD11b ${ }^{+}$F4/80 ${ }^{+} \mathrm{Ly}_{6 C^{+}}$ inflammatory macrophages can recruit and activate Th2 cells in lung tissue, and an imbalance in the Th1/Th2 immune response is considered to contribute to IPF pathogenesis (Morimoto et al., 2018). Macrophages are also an effective source of fibrotic cytokines (such as TGF- $\beta 1$ and PDGF), chemokines, and proteases (Gordon et al., 2014) and promote collagen synthesis by upregulating arginine metabolism (Wang et al., 2019). The pathogenesis of IPF is complex, and the disease course is difficult to predict. With the lack of effective treatments, patients inevitably progress to end-stage respiratory failure and have a higher risk of lung cancer (Caminati et al., 2019). However, the use of antifibrotic drugs such as pirfenidone (Costabel et al., 2017) and nintedanib (Richeldi et al., 2018) has been shown to slow down the fibrotic progression and likely improve progression-free survival. However, both drugs have noticeable gastrointestinal side effects (Bargagli et al., 2019). Although lung transplantation might improve the quality of life and survival, various challenges exist, such as a shortage of donor organs, immune rejection, and surgical complications (George et al., 2019). Accordingly, novel treatment strategies that are safe, effective, and convenient need to be urgently developed.

Mesenchymal stem cells (MSCs) reside in the perivascular niche in vivo. Upon local injury, they can be activated and recruited to the site of injury. By secreting bioactive molecules and regulating local immune response, they can establish a regeneration-promoting microenvironment (Caplan and Correa, 2011). In 1995, Lazarus et al. (1995) first tested MSCs as cellular drug preparations in human subjects. These have since emerged as the most extensively studied cells for experimental cell therapy globally. MSCs have the advantages of originating from a wide range of sources, easy availability, extensive proliferation properties, fewer ethical disputes, and low immunogenicity (Najar et al., 2019). After in vitro expansion and allogenic infusion, MSCs can still be recruited to sites of injury, promote epithelial tissue repair, and have powerful immunomodulatory properties such as inhibiting inflammation. These properties make MSCs ideal candidates for tissue engineering, regenerative medicine, and cell-based therapy for IPF (Lu and El-Hashash, 2019). It was initially thought that the benefits of MSC therapy were due to the replacement of damaged cells by these cells during tissue repair. However, subsequent experimental data revealed that the replacement of damaged cells was not the primary mechanism for MSC efficacy. Emerging evidence suggests that these cells exert their tissue repair-promoting and immunomodulatory effects through direct intercellular interactions or the secretion of bioactive products, termed the secretome, which comprises a series of bioactive molecules and extracellular vesicles (EVs). For their tissue repair-promoting effect, MSCs secrete various growth factors, including keratinocyte growth factor (FGF), hepatocyte growth factor (HGF), epidermal growth factor (EGF), and angiogenesis factors, which promote re-epithelialization and angiogenesis (Cahill et al., 2016; Lan et al., 2017; Li et al., 2017d). In addition, by direct mitochondrial transfer via connexin-mediated intercellular channels or EVs from MSCs to the damaged cells, MSCs can restore the ATP storage in recipient cells and repair cell functions (Morrison et al., 2017; Paliwal et al., 2018). For their immunomodulatory role, MSCs express a set of injury and molecular pathogen receptors, such as Toll-like receptors (Shirjang et al., 2017), and release a series of cytokines and chemokines, such as IL-1 receptor antagonist (IL-1RA) (Harrell et al., 2020) and soluble TNF receptor 1 (sTNFR1) (Ding et al., 2019), which have anti-inflammatory effects. Intercellular contact molecules or MSC-secreted soluble factors regulate the adaptive and innate immune system by inhibiting the maturation of $\mathrm{T}$ cells and dendritic cells, reducing $\mathrm{B}$ cell activation and proliferation, and inhibiting the cytotoxicity of natural killer cells (Ni et al., 2018; de Castro et al., 2019; He et al., 2020). MSCs modulate macrophage phenotypes by reducing the proportion of the pro-fibrotic cell phenotype (M2) and exerting anti-fibrotic effects (Willis et al., 2018; Luo et al., 2019). Furthermore, they directly counteract the fibrotic process by modulating the ratio of metalloproteinases/metalloproteinase tissue inhibitors, thereby reducing the content of collagen fibers and inhibiting lung remodeling (Xu et al., 2017; Chu et al., 2019). A summary of the therapeutic properties and mechanisms of MSCs in pulmonary fibrosis is shown in Figure 1.

\section{MULTIFACTOR SELECTION FOR THE TREATMENT OF IPF WITH MSCS}

Over the past 10 years, the therapeutic potential of MSCs for the restoration of injured lungs has received considerable interest. Knowledge of the mechanistic involvement of MSCs in pulmonary fibrosis is mainly derived from preclinical rodent models and in vitro analysis of human MSCs. Typical 


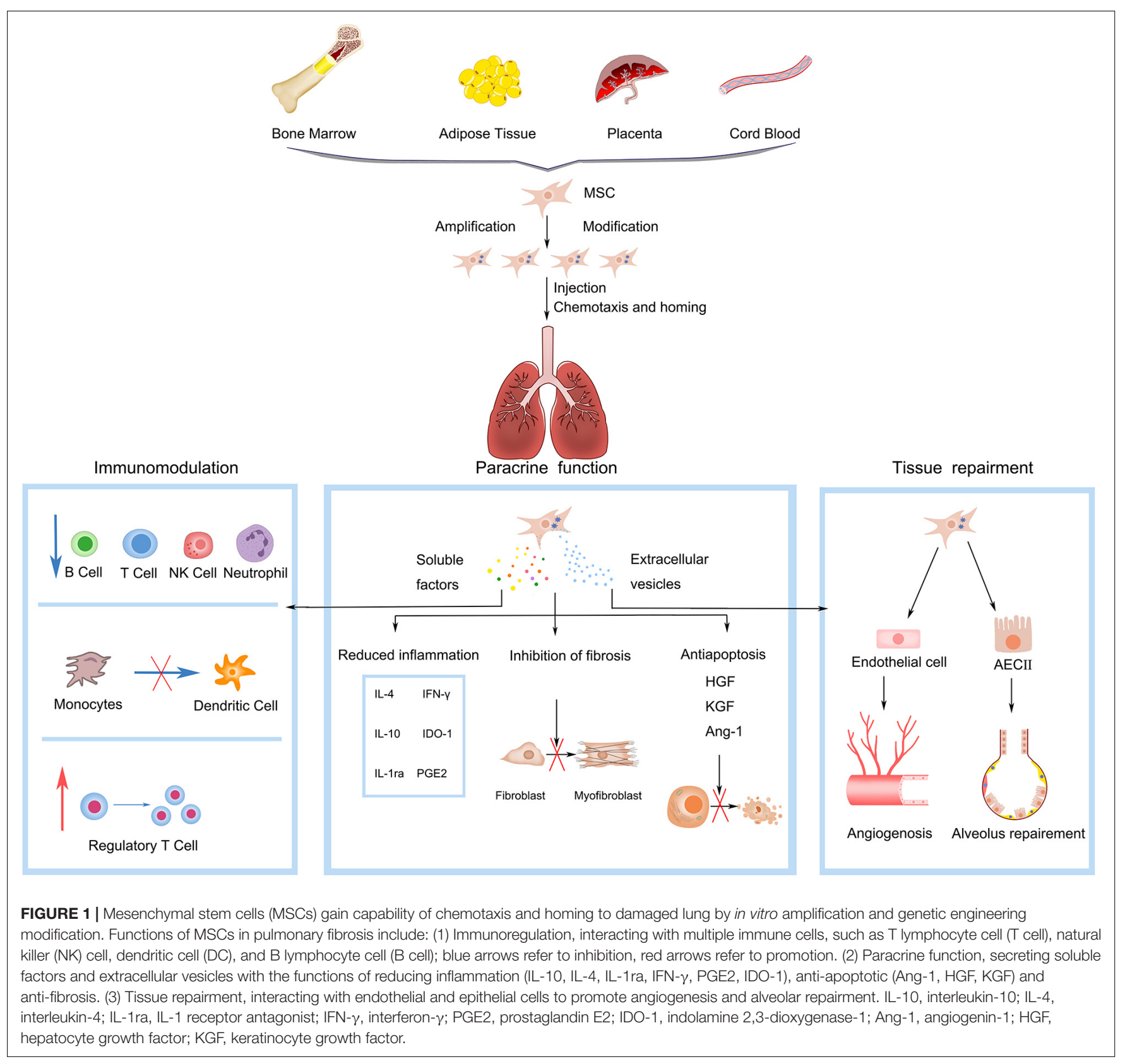

experimental protocols include the isolation of MSCs, plastic adherent cultures, harvesting of logarithmic growth phase cells, and adoptive transplantation in animal models of pulmonary fibrosis (Zhang et al., 2019; Gad et al., 2020; Periera-Simon et al., 2021). Although MSCs can reduce fibrosis, the various experimental variables obfuscate direct comparisons between different experiments. The tissue source, type of cells, delivery mode, dose, speed, and frequency of infusion are important parameters that affect the therapeutic effects of cell therapy, but these are challenging to test in large-scale human studies. Further preclinical experimental data on these parameters is necessary to improve the design of clinical intervention trials and ensure the safety and evidence-based nature of MSC treatments.

\section{Cell Type}

Even slight changes in cell type, cell source, and pretreatment methods can affect the efficacy of the final product. The design of MSC-based products must consider these key parameters for appropriate interpretation of results and to provide useful guidance for clinical trial design (Waszak et al., 2012).

\section{Comparison of MSCs From Different Tissues}

MSCs have been already isolated from a variety of adult and perinatal tissues, including but not limited to bone marrow, adipose tissue, dental pulp, menstrual blood, placenta, amnion, umbilical cord blood, and Wharton's jelly (Brown et al., 2019; Chen et al., 2020). MSCs from different sources exhibit different 
immunomodulatory abilities, in vitro proliferation properties and in vivo therapeutic functions. Among them, bone marrowderived MSCs (BM-MSCs) were the first type of isolated MSCs and the most commonly used cell type for lung diseases (Antunes et al., 2014b), which may have a better immunomodulatory ability than MSCs from other sources. Compared to adipose-derived MSCs (AD-MSCs), BM-MSCs have been demonstrated to more effectively regulate the phenotypic transition of macrophages in various lung injury models (Antunes et al., 2014a; Kitoko et al., 2018). By co-culturing them with spleen mononuclear cells, BM-MSC could suppress the expression of CD4 and CD8, whereas AD-MSCs could only inhibit the expression of CD4 (El-Sayed et al., 2019). When the immunomodulatory activity of MSCs was assessed based on their ability to suppress the phytohemagglutinin-induced proliferation of peripheral blood mononuclear cells, BM-MSCs showed significantly higher activity than AD-MSCs and Wharton's jelly MSCs (WJ-MSCs) (Petrenko et al., 2020). Therefore, BM-MSCs might be the best cell source for immune regulation.

The proliferation rate of MSCs also varies according to the tissue source. Recent studies have shown that average population doubling time (PDT) of WJ-MSCs is shorter than $24 \mathrm{~h}$ and stable for at least five passages (Petrenko et al., 2020). Choudhery et al. (2013) showed that PDT was shorter for umbilical cord MSCs (UC-MSCs) than for AD-MSCs. Another study demonstrated that compared to that with BM-MSCs, WJ-MSCs have a higher proliferation capacity (Batsali et al., 2017). That study also revealed differences in proliferation activity between BM-MSCs and AD-MSCs. From passage 2, BM-MSCs showed a longer PDT and entered senescence (Petrenko et al., 2020). Similar observations were reported by Kern et al. (2006), showing that BM-MSCs possessed the lowest proliferation capacity compared to that with AD-MSCs or UC-MSCs. Taken together, comparing UC-, AD-, and BM-MSCs, UC-MSCs show a highest proliferation activity and BM-MSCs show the lowest. In addition, the painful invasive isolation procedure for BM-MSCs has called for the identification of alternative sources for MSCs, and UCMSCs, which are treated as biological waste and usually discarded after birth, could be one of these choices.

In terms of in vivo therapeutic functions, especially for treating lung fibrosis, MSCs from different sources have also shown different effects. Pereira-Simon et al. studied the effect of various sources of MSCs in treating bleomycin (BLM)induced lung fibrosis in aging mice, including $\mathrm{AD}$ - and WJMSCs, and MSCs derived from the chorionic membrane (CSC) and chorionic villi. All sources decreased Aschroft score at day 10 post-treatment; further, all sources except CSC decreased hydroxyproline levels and $\alpha_{v}$-integrin and TNF- $\alpha$ mRNA levels. Meanwhile, only AD- and WJ-MSCs reduced AKT and MMP-2 activation, whereas Cav-1 was increased by AD-MSCs. Only AD-MSCs restored BLM-induced miR dysregulation of miR-29 and miR-199. These results showed that sources of MSCs might differ in their repair functions and underlying mechanisms (Periera-Simon et al., 2021). The latest single-cell RNA sequencing study has identified very significant transcriptional overlap between WJ- and AD-MSCs, thus potentially explaining some of these findings (Sun et al., 2020).
MSCs from different tissues applied in animal models of pulmonary fibrosis are demonstrated in Table $\mathbf{1}$.

Notably, there is also remarkable heterogeneity among distinct subpopulations of MSCs when viewed at single cell resolution, even from a single origin. Therefore, using the right cells from the right source in the appropriate disease model is likely to impact preclinical efficacy outcomes, and a method to ensure the homogeneity of MSCs is another challenge for the application of MSCs as a commercial drug. In a recent publication (Wu et al., 2020), clinical-grade human embryonic stem cell (hESC)-derived immune and stromal regulatory cells (IMRCs) produced under the requirements of good manufacturing practices (GMP) were reported by $\mathrm{Wu}$ et al. IMRCs avoid the ethical controversy of embryonic stem cells while maintaining relatively strong proliferative activity. The expression levels of immunomodulatory and anti-fibrosis genes were found to be higher than those of UC-MSCs. IMRCs derived from hESCs have the advantages of higher homogeneity and immunomodulatory ability and are thus worthy of further investigation.

\section{Donor Factors}

The therapeutic effect of MSCs is not only affected by tissue source but also by additional donor factors. Whether to use allogeneic or autologous MSCs is the first factor to be considered. Although MSCs from allogeneic donors could be removed faster than autologous ones (Ankrum et al., 2014), the "hit and run" mechanism of MSC function implies that longer residence time might not be crucial. Rodent models of acute lung injury have demonstrated that allogeneic transplantation of BM-MSCs is more effective than autologous transplantation of BM-MSCs, which could be associated with the limited autoimmunoregulatory ability of autologous MSCs (Antebi et al., 2018). Data from clinical trials support these findings. The results of the POSEIDON trial demonstrated that allogeneic MSCs were superior to autologous MSCs for treating patients with decompensated heart failure (Hare et al., 2017).

Further, intrinsic donor factors such as age, sex, and health status might affect the function of transplanted MSCs (Siegel et al., 2013; Brown et al., 2019). The number, proliferation, and differentiation potential of MSCs decrease with aging (Yang, 2018) or obesity (Baptista et al., 2015). Decreased superoxide dismutase activity has been detected in senescent MSCs, suggesting their weak antioxidant ability (Choudhery et al., 2014). Similarly, the anti-fibrotic effects of MSCs derived from aged donors are limited. Tashiro et al. (2015) investigated the difference between intratracheal infusion of AD-MSCs from young and old male mice after the administration of BLM. They observed that the lung tissue of BLM-treated mice receiving young donor $\mathrm{AD}-\mathrm{MSC}$ exhibited a decrease in fibrosis, inflammatory markers, oxidative stress, and apoptosis; in contrast, fibrosis and related markers were not decreased after treatment with aged donor AD-MSCs. Another study reported decreased cytokine and chemokine receptor expression in BM-MSCs from aged mice, which reduced the viability of these cells migrating to the injury site and attenuated their protective effects on lung tissue (Bustos et al., 2014). Cell therapy for pulmonary fibrosis is age-dependent. As such, 
TABLE 1 | MSCs from different tissues applied in animal models of pulmonary fibrosis.

\begin{tabular}{|c|c|c|c|c|c|c|c|}
\hline Source & PF model & Dose & Delivey & Time of cell transplantation & Repeated application & Efficacy results & References \\
\hline $\mathrm{BM}$ & Rat, amiodarone-induced & $3 \times 10^{6}$ & IV & 3 months a.t. & No & $\begin{array}{l}\downarrow \text { CC16, COL1A1, CTGF } \\
\uparrow \text { KGF levels }\end{array}$ & Abdel Halim et al., 2020 \\
\hline BM & Rat, BLM-induced & $1 \times 10^{6}$ & IV & 14 days a.t. & No & $\begin{array}{l}\downarrow \text { TGF- } \beta / \text { SMAD3 expression } \\
\uparrow \text { TNF- } \alpha \text { and IL- } 6\end{array}$ & Gad et al., 2020 \\
\hline BM & Rat, silica-induced & $2 \times 10^{6}$ & IV & 28 days a.t. & No & $\downarrow$ Wnt/ $\beta$-catenin signaling and EMT & Zhang et al., 2018 \\
\hline BM & Mice, BLM-induced & $5 \times 10^{5}$ & IV & 2 days a.t. & No & $\begin{array}{l}\downarrow \text { T-cell infiltration } \\
\uparrow \text { TNF- } \alpha, \text { IFN- } \gamma \text { and IP-10 }\end{array}$ & Ni et al., 2018 \\
\hline$A D$ & Rat, silicosis-induced & $5 \times 10^{5}$ & IV & 24 h a.t. & No & $\begin{array}{l}\downarrow \text { Caspase-3 protein } \\
\uparrow \text { Bcl-2/Bax ratio } \\
\uparrow \text { Anti-inflammatory factors }\end{array}$ & Chen et al., 2018 \\
\hline$A D$ & Rat, radiation-induced & $5 \times 10^{6}$ & IV & 2 h; 7 days; 2 h+ 7 days a.t. & Yes & $\begin{array}{l}\downarrow \text { EMT, TNF- } \alpha, \text { IL-1 and IL- } 6 \\
\uparrow I L-10 \text { and IL-2 }\end{array}$ & Zhang et al., 2019 \\
\hline$A D$ & Mice, BLM-induced & $5 \times 10^{5}$ & IV & 24 h a.t. & No & $\begin{array}{l}\downarrow \text { miR-199, caveolin- } 1 \text { and } \\
\text { phosphorylation of protein kinase B }\end{array}$ & Rubio et al., 2018 \\
\hline$A D$ & Mice, BLM-induced & $40 \times 10^{6} / \mathrm{kg}$ & IV & 3,6 and 9 days a.t. & Yes & $\begin{array}{l}\downarrow \text { Profibrotic and } \\
\text { pro-inflammatory gene transcripts }\end{array}$ & Reddy et al., 2016 \\
\hline WJ & Rat, BLM-induced & $5 \times 10^{6} 2.5 \times 10^{7}$ & IT & 21 days a.t. & No & $\begin{array}{l}\downarrow \text { EMT } \\
\uparrow M M P-9 \text { and TLR-4 }\end{array}$ & Chu et al., 2019 \\
\hline Placental & Mice, BLM-induced & $1 \times 10^{5}$ & IV & 3 days a.t. & No & $\begin{array}{l}\downarrow \text { HYP, TGF- } \beta \text {, TNF- } \alpha, \text { IL- } 1 \beta \text {; } \\
\downarrow \text { MyD88/TGF- } \beta \text { signaling axis }\end{array}$ & Li et al., 2017b \\
\hline Amniotic & Rat, paraquat-induced & $2 \times 10^{6}$ & IV & 6 h a.t. & No & $\begin{array}{l}\downarrow \text { Inflammatory CD3 }+ \text { T cell infiltration; } \\
\downarrow \text { TNF- } \alpha, \text { IL-6, TGF- } \beta 1 \text { and lactic acid }\end{array}$ & He et al., 2020 \\
\hline Menstrual blood & Mice, BLM-induced & $5 \times 10^{5}$ & IV & 2 and 7 days a.t. & Yes & $\begin{array}{l}\downarrow \text { Proliferation and differentiation of } \\
\text { MLFs; } \\
\downarrow \text { apoptosis of MLE- } 12 \text { cells }\end{array}$ & Chen et al., 2020 \\
\hline
\end{tabular}

PF, pulmonary fibrosis; BLM, bleomycin; IV, intravenous; IT, intratracheal; a.t., after treatment; BM, bone marrow; AD, adipose tissue; WJ, Wharton's jelly; CC16, clara cell secretory protein; KGF, keratinocyte growth factor; COL1A1, type I collagen; CTGF, connective tissue growth factor; TGF- $\beta$, tumor growth factor- $\beta$; IL-6, interleukin-6; TNF- $\alpha$, tumor necrosis factor alpha; IP-10, IFN- $\gamma$-induced protein 10; MMP-9, matrix metallopeptidase-9; TLR-4, toll-like receptor-4; EMT, epithelial-mesenchymal transition; MLFs, primary mouse lung fibroblasts; MLE-12, murine lung epithelia-12. 
TABLE 2 | Preconditioning strategies to improve MSC potency in animal models of pulmonary fibrosis.

\begin{tabular}{|c|c|c|c|c|}
\hline Preconditioning strategy & Cell source & PF model & Efficacy results & References \\
\hline Hypoxic environment & $\mathrm{BM}$ & Mice, BLM-induced & $\begin{array}{l}\uparrow \text { MSC survival rate } \downarrow I L-6 \text { and IL-1 } 1 \beta \text { mRNA } \\
\text { expression/protein levels } \downarrow \text { Lung injury score; collagen } \\
\text { deposition Improvement of pulmonary respiratory } \\
\text { functions }\end{array}$ & Lan et al., 2015 \\
\hline KGF & $\mathrm{BM}$ & $\begin{array}{l}\text { Neonatal rat, } \\
\text { hyperoxia-induced }\end{array}$ & $\begin{array}{l}\downarrow \text { Hydroxyproline in lung homogenates } \uparrow \text { SHH signaling } \\
\text { pathway } \downarrow \text { Lung injury histopathological index }\end{array}$ & Yao et al., 2013 \\
\hline OSM & $\mathrm{BM}$ & Mice, BLM-induced & $\begin{array}{l}\uparrow \text { Survival rates } \downarrow \text { Total cell counts and neutrophil counts } \\
\text { in BALF } \downarrow \text { Lung injury score, collagen deposition, } \uparrow \text { HGF } \\
\text { protein levels } \downarrow \text { TGF- } \beta \text {, CTGF, MMP9 and TIMP1 mRNA } \\
\text { levels in lung homogenate }\end{array}$ & Lan et al., 2017 \\
\hline G-CSF & $\mathrm{BM}$ & Mice, BLM-induced & $\begin{array}{l}\uparrow \text { CXCR4 expression } \uparrow \text { homing to the lung } \uparrow \text { antifibrotic } \\
\text { effects }\end{array}$ & Zhao et al., 2019 \\
\hline $\mathrm{N}$-acetylcysteine & Embryonic tissues & Mice, BLM-induced & $\begin{array}{l}\downarrow \text { ROS levels, apoptotic lung cells } \downarrow \text { Lung injury score, } \\
\text { collagen deposition } \downarrow \text { IL-6, TNF- } \alpha \text {, and IL-1 } 1 \beta \text { protein } \\
\text { levels in BALF } \uparrow \text { Survival rates }\end{array}$ & Wang et al., 2013 \\
\hline Overexpress BMP-7 gene & $\mathrm{BM}$ & Rat, silicosis-induced & $\begin{array}{l}\downarrow \text { Lung injury score; collagen deposition } \\
\downarrow \text { Hydroxyproline in lung homogenates } \\
\uparrow \text { SP-C and AQP-5 protein levels in lung homogenate }\end{array}$ & Li et al., 2017c \\
\hline Overexpress Decorin gene & UC & Mice, radiation-induced & $\begin{array}{l}\downarrow \text { Apoptotic lung cells } \\
\downarrow \text { Lung injury score } \\
\downarrow \text { Chemokines and inflammatory cytokines } \\
\downarrow \text { Tregs }\end{array}$ & Liu et al., 2018 \\
\hline Overexpress ACE2 gene & UC & Mice, BLM-induced & $\begin{array}{l}\downarrow \text { TNF- } \alpha, \text { IFN- } \gamma, \text { TGF- } \beta, \text { IL-1, IL-2, IL-6 } \\
\downarrow \text { Lung injury score; hydroxyproline concentration } \\
\uparrow S O D, \text { GSH, ACE2 and IL-10 }\end{array}$ & Min et al., 2015 \\
\hline Overexpress miRNA let-7d & $\mathrm{BM}$ & Mice, BLM-induced & $\begin{array}{l}\uparrow \text { mice weight and survival } \\
\downarrow \text { Collagen- } 1 \text { expression } \\
\downarrow \text { CD45-positive cells }\end{array}$ & Huleihel et al., 2017 \\
\hline
\end{tabular}

KGF, keratinocyte growth factor; OSM, oncostatin M; G-CSF, granulocyte colony-stimulating factor; CXCR4, CXC chemokine receptor-4; TIMP1, tissue inhibitor of metalloproteinase 1; BMP7, bone morphogenetic protein-7; UC, umbilical cord; ACE2, angiotensin-converting enzyme 2 gene; DEG, differentially expressed genes.

donor age should be considered carefully in cell therapy for IPF patients, as transplantation results can vary according to the age of the cell donor. Donor comorbidities might also influence the potency of MSCs. BM-MSCs from patients with IPF exhibited signs of senescence and did not prevent BLM-induced pulmonary fibrosis in mice (Cárdenes et al., 2018). Given that IPF patients are geriatric, the efficacy of autologous transplantation may be limited. Therefore, allogeneic transplantation might be more recommended, and MSCs from healthy young donors should be preferred.

\section{Pretreatment of MSCs}

Preclinical animal data indicate that various strategies might enhance the pharmaceutical efficacy of MSCs before infusion, such as changing cell culture methods, adding cytokines or drugs to the culture medium, and modifying MSCs via genetic engineering (Silva et al., 2018; Zhao et al., 2019). MSCs cultured under hypoxic conditions promote the anti-fibrotic activity of radiation-induced and BLM-induced pulmonary fibrosis in murine models. This enhanced potency of MSCs is realized by various mechanisms, including the upregulation of antiinflammatory, anti-apoptotic, and antioxidant gene expression, as well as changes in proliferation and Akt signaling (Lan et al., 2015; Li et al., 2017a). KGF is a key growth factor involved in the repair of lung epithelial damage. Pretreatment of MSCs with KGF increases their ability to prevent hyperoxia-induced pulmonary fibrosis, which could be underscored by the increased homing of MSCs to fibrotic lung tissue (Yao et al., 2013). Pretreatment with oncostatin M (OSM) prolongs the survival time of transplanted MSCs, upregulates HGF secretion, and enhances the effectiveness of transplantation in the treatment of pulmonary fibrosis (Lan et al., 2017). Pretreatment of MSCs with the diabetes drug pioglitazone in vitro increases the expression of VEGF (Hong et al., 2016). Further, MSCs preincubated with the antioxidant $\mathrm{N}$-acetylcysteine exhibit increased intracellular glutathione levels and antioxidant capacity (Wang et al., 2013).

In addition to the preconditioning of MSCs, genetic engineering and stem cell biology to treat diseases has significant therapeutic potential (Min et al., 2015; Huleihel et al., 2017; Liu et al., 2018). In a rat model of silicon dioxide-induced pulmonary fibrosis, allogeneic BM-MSCs modified with BMP-7 were found to inhibit pulmonary fibrosis by reducing epithelialmesenchymal transition. Compared to that with unmodified BM-MSCs, modified BM-MCSs exhibit enhanced anti-fibrotic capacity (Yang et al., 2016; Li et al., 2017c). The transduction of MSCs with IL-10 or HGF prevents serious side effects caused by the application of MSCs, which might be related to the excessive release of TGF- $\beta$ from these cells (Islam et al., 2019). Preconditioning strategies and genetic modifications to improve MSC potency in animal models of pulmonary fibrosis are demonstrated in Table 2. 
In general, preconditioning or genetic modifications can enhance MSC therapeutic potential. However, the adverse effects of pretreatment of MSCs are less well studied. For example, researchers have applied viral-based gene modification strategies because this system is efficient and stable. However, viral transduction is associated with many risks, such as immunogenicity and chromosomal integration risks (Oggu et al., 2017). Therefore, further research is needed to evaluate both the efficacy and safety of pretreated MSCs.

\section{Intervention Time}

The American Thoracic Society advocates for the intratracheal BLM mouse model as the optimal animal model for preclinical testing (Jenkins et al., 2017). The advantage of using BLM in the mouse trachea is the requirement for only a single infusion, enabling the reproduction of fibrotic diseases in a short time. The BLM model can be divided into three stages. The first 3 days after installation is the inflammation triggering stage. Fibroblasts proliferate after 7 days, and the fibrosis model is established 15 days later (Serrano-Mollar, 2018). In the early stage of the mouse inflammation model, stem cell therapy reduces inflammatory factors, activates fibroblasts and collagen deposition promotes, epithelial cell repair, and exerts a significant protective effect on damaged tissues (Li et al., 2017b; Rubio et al., 2018). Early experimental data only support the potential improving effect of MSC administration on fibrotic lung diseases if administered in the early stage of the disease, during active inflammation. However, most patients who present with respiratory symptoms have already developed pulmonary fibrosis to varying degrees. As using MSCs for early intervention is impractical, it is necessary to evaluate the beneficial effect of MSC transplantation on established lung fibrosis. Fortunately, several recent studies have shown that MSCs also have a therapeutic effect on established pulmonary fibrosis models. In a BLM-induced rat pulmonary fibrosis model, BM-MSCs were administered 14 days after BLM injection. MSCs inhibited the expression of TGF- $\beta / \mathrm{Smad} 3$ and reduced the deposition of collagen fibers in lung tissue (Gad et al., 2020). In another study, UC-MSCs were administered 21 days after the intratracheal instillation of BLM. UC-MSCs activated the host macrophages to synthesize MMP-9 and degrade existing collagen (Chu et al., 2019). In a silica-induced fibrosis model, the effects of late MSC transplantation were also promising (Zhang et al., 2018). These experimental data indicated that although early MSC intervention might be more effective, MSCs application at a later time could be also beneficial, supporting such strategies to treat pulmonary fibrosis.

\section{Interventional Approach}

Understanding the biodistribution of cells in stem cell therapy is an important step in translating preclinical findings into clinical settings. Two methods are commonly used to introduce MSCs into target tissues, systemic and local delivery (Kean et al., 2013; Cardenes et al., 2019). In most preclinical studies, MSCs are delivered via the intravenous (IV) route in pulmonary fibrosis models (Reddy et al., 2016; Chen et al., 2018; Moroncini et al., 2018; Ni et al., 2018; Wu et al., 2020). Intravascular delivery is based on the theory that (1) the delivered MSCs will receive and respond to the injury signals released by damaged airway tissue, and these stimuli will induce MSCs to home from the blood vessels to the injury site (Nitzsche et al., 2017; Abdel Halim et al., 2020) and (2) that MSCs will interact with distant cells via endocrine pathways to promote regeneration (Khatri et al., 2018; Willis et al., 2018). The preferred choice of the intravenous route might be due to easy and practical procedures, which allow for repeated transplantation.

In contrast, local administration is advantageous in that it prolongs the cell half-life, improves utilization, and reduces side effects on other organs (off-target effects). In pulmonary diseases, intratracheal (IT) route is also used, and showed effects in IPF models (Chu et al., 2019; Ji et al., 2020). In addition to traditional IT injection, another IT delivery method is aerosol technology, which is widely used to deliver pharmaceutically active substances to the lungs (Ehrmann et al., 2020). Kim et al. (2016) reported that spraying human amniotic MSCs onto substrates of different stiffnesses enabled cell survival. In preclinical studies of acute and chronic lung injury in rabbits, Kardia et al. (2018) observed that aerosol-based cell delivery was a feasible technique to deliver cells directly to the lungs and to evenly distribute nebulized solutions containing cells. In addition to stem cells, aerosol technology is an ideal tool for delivering cell-derived biologics, particularly MSCs-EVs (McCarthy et al., 2020).

Regarding the effect of different approaches on the therapeutic effect of MSCs, Cardenes et al. (2019) compared the IT or IV routes of bone marrow-derived multipotent adult progenitor cell administration in an ovine model of acute respiratory distress syndrome (ARDS). PET/CT images revealed that ITadministered cells remained at the administration site and no changes were observed within $5 \mathrm{~h}$, whereas intravenously administered cells exhibited a wide biological distribution, with the highest cell concentration in the lungs. Meanwhile, the biological distribution of cells varies depending on the method of administration, and both routes of administration led to comparable therapeutic effects. In emphysema models, different routes of delivery MSCs showed different effects. IV injection of MSCs could reduce the deterioration in lung function, but no protective effect was observed in the IT route. IV injection of MSCs creates a systemic anti-inflammatory response via the systemic circulation on the endothelial surface of the pulmonary vasculature. Thus, the anti-inflammatory milieu on the endothelial side produced by MSCs injected via the vein could decrease the vascular inflammation shown to be present in the elastase-induced emphysema model (Tibboel et al., 2014). It is worth noting that the effect of different MSCs intervention approaches on lung diseases may be different from other diseases. As in perianal fistulizing Crohn's disease (PFCD), a meta-analysis published in 2015 showed that local injection of MSCs into fistula lesions has considerable therapeutic benefit, which is more significant than systematic administration (Dave et al., 2015). It is speculated that MSCs maintain local anti-inflammatory effects by sending paracrine signals to neighboring cells. Whereas the systemic application of MSCs may not allow a sufficient number of MSCs to migrate to the inflammatory site, and the dosage could be limited by the potential systematic side-effect (Gallo et al., 2020). This difference of therapeutic effect may 
TABLE 3 | Different delivery routes of MSCs in animal models of pulmonary disease.

\begin{tabular}{|c|c|c|c|c|c|}
\hline Delivery & Cell Source & Animal models & Dose & Efficacy Results & References \\
\hline Intraperitoneal & BM & BPD & $1 \times 10^{5}$ & $\begin{array}{l}\text { Improves survival rate } \\
\text { Prevents pulmonary fibrosis }\end{array}$ & Zhang et al., 2012 \\
\hline Nebulization & UC-CM/BM-CM & ARDS & $10 \mathrm{~mL}$ & $\begin{array}{l}\text { Anti-bacterial ability remained after } \\
\text { nebulization }\end{array}$ & McCarthy et al., 2020 \\
\hline IV & UC & Lung fibrosis & $2.5 \times 10^{5}$ & Anti-fibrotic activity & Moroncini et al., 2018 \\
\hline IT & Amniotic & Lung fibrosis & $1 \times 10^{6}$ & Inhibit B cell activation & Cargnoni et al., 2020 \\
\hline IV vs. IT & $\mathrm{BM}$ & Pulmonary emphysema & IV: $1 \times 10^{5}$ IT: $5 \times 10^{5}$ & IV is better than IT & Tibboel et al., 2014 \\
\hline IV vs. IT & $\mathrm{BM}$ & ARDS & $\begin{array}{l}\text { IV: } 10 \times 10^{6} \mathrm{cells} / \mathrm{kg} \\
\mathrm{IT}: 1 \times 10^{6} \mathrm{cells} / \mathrm{kg}\end{array}$ & IV is similar to IT & Cardenes et al., 2019 \\
\hline
\end{tabular}

CM, conditioned medium; BPD, bronchopulmonary dysplasia.

be due to the different characteristics of different diseases. In pulmonary fibrosis, the focus is often diffusely distributed, rather than concentrated in a certain point. Therefore, the effect of tracheal administration and local administration in PFCD is not the same, which may be the reason why IV and IT routes are both effective in pulmonary fibrosis. Further, the intraperitoneal injection of MSCs was reported to have therapeutic effects on pulmonary fibrosis induced by repeated BLM treatments (Zhang et al., 2012). This suggests that the direct contact of stem cells with lung tissue might be unnecessary, or different mechanisms may play a role in different interventional approaches, which is worthy of further study in details. The effects of different delivery methods on MSC efficacy are shown in Table 3.

\section{Infusion Dose and Speed}

Similar to drugs, the therapeutic effects of MSCs are dosedependent (Jun et al., 2011; Schlosser et al., 2019). Therefore, the minimum effective dose and optimal dose range of cell preparations need to be further specified before their widespread application. Early dosage is difficult to evaluate from traditional preclinical pharmacokinetics and pharmacodynamics, but previous clinical experience might provide some guidance. An analysis of clinical trials involving MSCs from 2004 to 2018 by Kabat et al. (2020) revealed that the minimum effective dose (MED) was 70-190 × $10^{6}$ MSCs per patient among trials with positive results reported. Only four of the trials reported data on dose-effect relationships and indicated that the MED range was narrow (between 100 and $150 \times 10^{6}$ MSCs per patient). The clinical effects are insufficient if the number of cells is too low, but excessive cells could increase the risk of pulmonary embolism (Janowski et al., 2013; Liu et al., 2017), leading to increased mortality. Anticoagulation therapy with heparin before the application of high-dose MSCs might prevent serious adverse events (Liao et al., 2017). In addition, infusion speed is a key factor that affects the safety of cell therapy (Janowski et al., 2013). In experiments on rats, the risk of stroke was found to be significantly increased when the infusion speed exceeded $1 \mathrm{~mL} / \mathrm{min}$, whereas a lower speed $(0.2 \mathrm{~mL} / \mathrm{min})$ was relatively safe.

\section{Interval and Frequency of Intervention}

The majority of studies have focused on the safety of stem cell transplantation and only employed MSCs once. However, following preliminary safety tests, it is necessary to address the issues of the administration interval and frequency. Technological advances in in vivo tracing have enabled superior tracking of the biodistribution and clearance of MSCs in the body to optimize delivery strategies. It has been reported that the time that MSCs remain in lung tissue varies from 7 days to 4 months, depending on the detection method and disease model used (Leibacher and Henschler, 2016; Abdel Halim et al., 2020). Poggio et al. (2018) compared the intervention strategies of MSCs administered once and twice with a second dose weekly and reported that repeated administration had stronger immunosuppressive effects on $\mathrm{T}$ cells, and mainly $\mathrm{CD}^{+} \mathrm{T}$ cells. In a murine model of BLM-induced pulmonary fibrosis, repeated administration of MSCs three times every 3 days had comparable antifibrotic effects to the continuous administration of pirfenidone (Reddy et al., 2016). Similar results were obtained in rat models of radiation-induced pulmonary fibrosis (Zhang et al., 2019). Considering the short half-life of donor MSCs in vivo, multiple transplantation times is a promising solution.

\section{EFFICACY AND SAFETY OF CLINICAL TRIALS WITH DIFFERENT PARAMETERS}

Preclinical studies in rodents have achieved unprecedented positive results, which will encourage the translation of MSC therapy into clinical trials. Currently, multiple phase I clinical trials have been conducted to ensure the safety of MSC treatment (Table 4). A phase Ib study of the intrabronchial administration of autologous AD-MSCs in IPF patients reported acceptable safety and improved parameters of life quality (Tzouvelekis et al., 2013). The recently published longitudinal results of this study further supported the safety of cellular therapy. In 14 patients, the 2 year survival rate was $100 \%$ after the first dose, with progression-free survival of up to 26 months without tumors (Ntolios et al., 2018). In addition, studies on the intravenous injection of placenta-derived MSCs (Chambers et al., 2014) and BM-MSCs (Liu et al., 2015; Glassberg et al., 2017; Averyanov et al., 2020) have revealed that it is safe for IPF patients to receive up to $2 \times 10^{8}$ cells without experiencing hemodynamic abnormalities, which relieves the concern that the application of MSCs to a damaged vascular system might increase the risk of pulmonary embolism. These clinical trials have paved the way for recruiting more patients and further studies on dosage. 


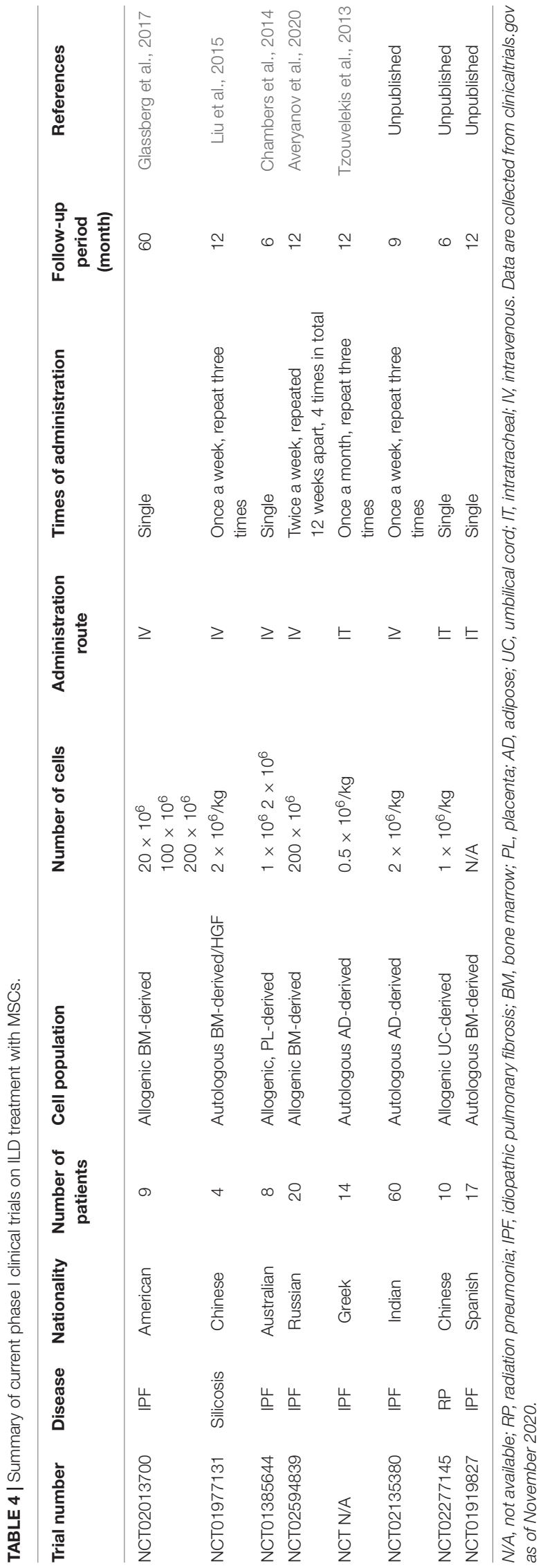

The results of the AETHER trial (Glassberg et al., 2017) demonstrated the safety of intravenous infusion of allogeneic BM-MSCs in IPF patients. No serious adverse events were observed during the 60-week follow-up period, and the most common adverse reactions were bronchitis and cold. The predicted value of FVC decreased by $3.0 \%$ on average, and the predicted value of carbon monoxide diffusing capacity (DLCO) decreased by an average of $5.4 \%$, which was below the internationally recognized threshold of disease progression. Comparisons of patients receiving doses of $2 \times 10^{7}$ and those receiving $10 \times 10^{7}$ MSCs revealed that the HRCT fibrosis score of patients in the high-dose group progressed more slowly, with a slower rate of DLCO decrease and improved treatment effects (Fishman et al., 2019). These results suggest that further largescale dose escalation studies should be conducted to determine the optimal dose of MSCs.

In clinical trials, the strategy of MSC pretreatment has been applied to treat pulmonary fibrosis. For example, $2 \times 10^{6}$ cells $/ \mathrm{kg}$ of autologous BM-MSCs were infused intravenously into four silicosis patients twice per week for three consecutive weeks. These MSCs were transfected with HGF $c D N A$ vectors before infusion (Liu et al., 2015). Patient clinical symptoms such as cough and chest tightness were alleviated after 6 months, with a significant improvement in lung function, serum IgG levels, and circulating T-lymphocyte levels, thereby confirming the safety of premodified MSCs.

These trials used autologous or allogeneic BM-MSCs, ADMSCs, PL-MSCs, and UC-MSCs, different doses ranging from 1 to $200 \times 10^{6}$ MSCs, and different routes of administration thus making comparisons difficult. To date, the majority of clinical trials are in the early stages of evaluating the safety, feasibility, tolerance, and efficacy of cell therapy. The limitations of these studies include small sample sizes and a lack of randomization and/or placebo controls. Cell therapy requires the consideration of further optimization of stem cell type, in vitro modification, intervention schemes, routes of administration, and suitable dosage. Nevertheless, these reports suggest that stem cell transplantation in IPF is initially safe and has some benefits, and standardized protocols might encourage scientists to explore the potential of MSC therapy for IPF patients.

\section{OTHER FACTORS POTENTIALLY AFFECTING THE SAFETY OF MSC THERAPY}

Data from preclinical animal experiments are encouraging, and serious adverse events have not been reported in clinical trials, highlighting the safety and feasibility of MSC transplantation. Nonetheless, clinical trials must be conducted with caution. Since TGF- $\beta$ has been validated as a causative factor of fibrosis (Kim et al., 2018), there are concerns that its secretion by MSCs could promote abnormal fibroblast populations in the context of fibrosis and immune system abnormalities (Salazar et al., 2009). Correcting the microenvironment prior to the use of MSCs will enhance the benefits and eliminate the side effects of fibrosis (Islam et al., 2019). Another concern is the 
possibility of tumor formation after transplantation (Ben-David et al., 2011). However, Sensebé et al. (2012) refuted this view and proposed that human adult stem cells and MSCs cultured in vitro have strong genetic stability. Systematic evaluation and meta-analyses of clinical trials in stem cell therapy for various respiratory diseases have not reported serious adverse events after MSC transplantation such as the formation of transplantrelated tumors (Zhao et al., 2017). The quality control of MSCs is a critical step before the clinical application of regenerative therapy. MSCs used in clinical settings should conform with the principles of GMP (Torre et al., 2015; Samsonraj et al., 2017). Further refinements are required to ensure the stability of cell preparations, as factors such as donor heterogeneity, in vitro amplification, immunogenicity, and cryopreservation might influence the therapeutic efficiency and safety of MSCs (François et al., 2012; Wang and Han, 2019).

\section{CONCLUSION}

With the developments in regenerative medicine technology, stem cell therapy has been tested for safety and efficacy in various lung diseases in the last decade. Based on the results of IPF preclinical animal models and clinical trials, as well as the urgent need for new treatments, well-designed and optimized clinical trials of MSC therapy for IPF patients are warranted. Safety

\section{REFERENCES}

Abdel Halim, A. S., Ahmed, H. H., Aglan, H. A., Abdel Hamid, F. F., and Mohamed, M. R. (2020). Role of bone marrow-derived mesenchymal stem cells in alleviating pulmonary epithelium damage and extracellular matrix remodeling in a rat model of lung fibrosis induced by amiodarone. Biotech. Histochem. 10, 1-13. doi: 10.1080/10520295.2020.181 4966

Ankrum, J. A., Ong, J. F., and Karp, J. M. (2014). Mesenchymal stem cells: immune evasive, not immune privileged. Nat. Biotechnol. 32, 252-260. doi: 10.1038/nbt. 2816

Antebi, B., Walker, K. P. III, Mohammadipoor, A., Rodriguez, L. A., Montgomery, R. K., Batchinsky, A. I., et al. (2018). The effect of acute respiratory distress syndrome on bone marrow-derived mesenchymal stem cells. Stem Cell Res. Ther. 9:251. doi: 10.1186/s13287-018-0981-3

Antunes, M. A., Abreu, S. C., Cruz, F. F., Teixeira, A. C., Lopes-Pacheco, M., Bandeira, E., et al. (2014a). Effects of different mesenchymal stromal cell sources and delivery routes in experimental emphysema. Respir. Res. 15:118. doi: 10. 1186/s12931-014-0118-x

Antunes, M. A., Laffey, J. G., Pelosi, P., and Rocco, P. R. (2014b). Mesenchymal stem cell trials for pulmonary diseases. J. Cell. Biochem. 115, 1023-1032. doi: $10.1002 /$ jcb. 24783

Averyanov, A., Koroleva, I., Konoplyannikov, M., Revkova, V., Lesnyak, V., Kalsin, V., et al. (2020). First-in-human high-cumulative-dose stem cell therapy in idiopathic pulmonary fibrosis with rapid lung function decline. Stem Cells Transl. Med. 9, 6-16. doi: 10.1002/sctm.19-0037

Ballester, B., Milara, J., and Cortijo, J. (2019). Idiopathic pulmonary fibrosis and lung cancer: mechanisms and molecular targets. Int. J. Mol. Sci. 20:593. doi: 10.3390/ijms20030593

Baptista, L. S., Silva, K. R., and Borojevic, R. (2015). Obesity and weight loss could alter the properties of adipose stem cells? World J. Stem Cells 7, 165-173. doi: 10.4252/wjsc.v7.i1.165

Bargagli, E., Piccioli, C., Rosi, E., Torricelli, E., Turi, L., Piccioli, E., et al. (2019). Pirfenidone and Nintedanib in idiopathic pulmonary fibrosis: real-life experience in an Italian referral centre. Pulmonology 25, 149-153. doi: 10.1016/ j.pulmoe.2018.06.003 should be the primary concern in early clinical trials, followed by clinical and biological efficacy. Significant parameters that will influence the effectiveness of MSCs must be considered before conducting large-scale trials, including cell source, the donor and recipient, route, dose and time of administration, and pretreatment of MSCs, to maximize their therapeutic efficacy while minimizing potential side effect.

\section{AUTHOR CONTRIBUTIONS}

SY and PL conceived of the idea, performed the literature search, collected the data, and drafted the entire article. YJ performed a review of clinical trials. $\mathrm{ZW}, \mathrm{HD}$, and $\mathrm{CW}$ revised the manuscript. All authors contributed to the article and approved the final version of the manuscript.

\section{FUNDING}

This work was supported by the Chinese Academy of Medical Sciences, Science and Technology Innovation in Medicine and Health Project (Major Collaborative Innovation Project 2018I2M-1-0001) and Non-profit Central Research Institute Fund of Chinese Academy of Medical Sciences (No. 2019PT320021).

Barratt, S. L., Creamer, A., Hayton, C., and Chaudhuri, N. (2018). Idiopathic pulmonary fibrosis (IPF): an overview. J. Clin. Med. 7:201. doi: 10.3390/ jcm7080201

Batsali, A. K., Pontikoglou, C., Koutroulakis, D., Pavlaki, K. I., Damianaki, A., Mavroudi, I., et al. (2017). Differential expression of cell cycle and WNT pathway-related genes accounts for differences in the growth and differentiation potential of Wharton's jelly and bone marrow-derived mesenchymal stem cells. Stem Cell Res. Ther. 8:102. doi: 10.1186/s13287-017-0555-9

Ben-David, U., Mayshar, Y., and Benvenisty, N. (2011). Large-scale analysis reveals acquisition of lineage-specific chromosomal aberrations in human adult stem cells. Cell Stem Cell 9, 97-102. doi: 10.1016/j.stem.2011.06.013

Brown, C., Mckee, C., Bakshi, S., Walker, K., Hakman, E., Halassy, S., et al. (2019). Mesenchymal stem cells: cell therapy and regeneration potential. J. Tissue Eng. Regen. Med. 13, 1738-1755. doi: 10.1002/term.2914

Bustos, M. L., Huleihel, L., Kapetanaki, M. G., Lino-Cardenas, C. L., Mroz, L., Ellis, B. M., et al. (2014). Aging mesenchymal stem cells fail to protect because of impaired migration and antiinflammatory response. Am. J. Respir. Crit. Care Med. 189, 787-798. doi: 10.1164/rccm.201306-1043OC

Cahill, E. F., Kennelly, H., Carty, F., Mahon, B. P., and English, K. (2016). Hepatocyte growth factor is required for mesenchymal stromal cell protection against bleomycin-induced pulmonary fibrosis. Stem Cells Transl. Med. 5, 1307-1318. doi: 10.5966/sctm.2015-0337

Caminati, A., Lonati, C., Cassandro, R., Elia, D., Pelosi, G., Torre, O., et al. (2019). Comorbidities in idiopathic pulmonary fibrosis: an underestimated issue. Eur. Respir. Rev. 28:190044. doi: 10.1183/16000617.0044-2019

Caplan, A. I., and Correa, D. (2011). The MSC: an injury drugstore. Cell Stem Cell 9, 11-15. doi: 10.1016/j.stem.2011.06.008

Cárdenes, N., Álvarez, D., Sellarés, J., Peng, Y., Corey, C., Wecht, S., et al. (2018). Senescence of bone marrow-derived mesenchymal stem cells from patients with idiopathic pulmonary fibrosis. Stem Cell Res. Ther. 9:257. doi: 10.1186/s13287018-0970-6

Cardenes, N., Aranda-Valderrama, P., Carney, J. P., Sellares Torres, J., Alvarez, D., Kocyildirim, E., et al. (2019). Cell therapy for ARDS: efficacy of endobronchial versus intravenous administration and biodistribution of MAPCs in a large animal model. BMJ Open Respir. Res. 6:e000308. doi: 10.1136/bmjresp-2018000308 
Cargnoni, A., Romele, P., Bonassi Signoroni, P., Farigu, S., Magatti, M., Vertua, E., et al. (2020). Amniotic MSCs reduce pulmonary fibrosis by hampering lung B-cell recruitment, retention, and maturation. Stem Cells Transl. Med. 9, 1023-1035. doi: 10.1002/sctm.20-0068

Chambers, D. C., Enever, D., Ilic, N., Sparks, L., Whitelaw, K., Ayres, J., et al. (2014). A phase $1 \mathrm{~b}$ study of placenta-derived mesenchymal stromal cells in patients with idiopathic pulmonary fibrosis. Respirology 19, 1013-1018. doi: 10.1111/resp. 12343

Chen, S., Cui, G., Peng, C., Lavin, M. F., Sun, X., Zhang, E., et al. (2018). Transplantation of adipose-derived mesenchymal stem cells attenuates pulmonary fibrosis of silicosis via anti-inflammatory and anti-apoptosis effects in rats. Stem Cell Res. Ther. 9:110. doi: 10.1186/s13287-018-0846-9

Chen, X., Wu, Y., Wang, Y., Chen, L., Zheng, W., Zhou, S., et al. (2020). Human menstrual blood-derived stem cells mitigate bleomycin-induced pulmonary fibrosis through anti-apoptosis and anti-inflammatory effects. Stem Cell Res Ther 11:477. doi: 10.1186/s13287-020-01926-x

Choudhery, M. S., Badowski, M., Muise, A., and Harris, D. T. (2013). Comparison of human mesenchymal stem cells derived from adipose and cord tissue. Cytotherapy 15, 330-343. doi: 10.1016/j.jcyt.2012.11.010

Choudhery, M. S., Badowski, M., Muise, A., Pierce, J., and Harris, D. T. (2014). Donor age negatively impacts adipose tissue-derived mesenchymal stem cell expansion and differentiation. J. Transl. Med. 12:8. doi: 10.1186/1479-5876$12-8$

Chu, K. A., Wang, S. Y., Yeh, C. C., Fu, T. W., Fu, Y. Y., Ko, T. L., et al. (2019). Reversal of bleomycin-induced rat pulmonary fibrosis by a xenograft of human umbilical mesenchymal stem cells from Wharton's jelly. Theranostics 9, 6646-6664. doi: 10.7150/thno.33741

Costabel, U., Albera, C., Lancaster, L. H., Lin, C. Y., Hormel, P., Hulter, H. N., et al. (2017). An open-label study of the long-term safety of pirfenidone in patients with idiopathic pulmonary fibrosis (RECAP). Respiration 94, 408-415. doi: 10.1159/000479976

Dave, M., Mehta, K., Luther, J., Baruah, A., Dietz, A. B., and Faubion, W. A. Jr. (2015). Mesenchymal stem cell therapy for inflammatory bowel disease: a systematic review and meta-analysis. Inflamm. Bowel Dis. 21, 2696-2707. doi: 10.1097/MIB.0000000000000543

de Castro, L. L., Lopes-Pacheco, M., Weiss, D. J., Cruz, F. F., and Rocco, P. R. M. (2019). Current understanding of the immunosuppressive properties of mesenchymal stromal cells. J. Mol. Med. (Berl.) 97, 605-618. doi: 10.1007/ s00109-019-01776-y

Ding, X. F., Liang, H. Y., Sun, J. Y., Liu, S. H., Kan, Q. C., Wang, L. X., et al. (2019). Adipose-derived mesenchymal stem cells ameliorate the inflammatory reaction in CLP-induced septic acute lung injury rats via sTNFR1. J. Cell. Physiol. 234, 16582-16591. doi: 10.1002/jcp.28329

Ehrmann, S., Schmid, O., Darquenne, C., Rothen-Rutishauser, B., Sznitman, J., Yang, L., et al. (2020). Innovative preclinical models for pulmonary drug delivery research. Expert Opin. Drug Deliv. 17, 463-478. doi: 10.1080/17425247. 2020.1730807

El-Sayed, M., El-Feky, M. A., El-Amir, M. I., Hasan, A. S., Tag-Adeen, M., Urata, Y., et al. (2019). Immunomodulatory effect of mesenchymal stem cells: cell origin and cell quality variations. Mol. Biol. Rep. 46, 1157-1165. doi: 10.1007/s11033018-04582-w

Fishman, J. E., Kim, G. J., Kyeong, N. Y., Goldin, J. G., and Glassberg, M. K. (2019). Intravenous stem cell dose and changes in quantitative lung fibrosis and DLCO in the AETHER trial: a pilot study. Eur. Rev. Med. Pharmacol. Sci. 23, 7568-7572.

François, M., Copland, I. B., Yuan, S., Romieu-Mourez, R., Waller, E. K., and Galipeau, J. (2012). Cryopreserved mesenchymal stromal cells display impaired immunosuppressive properties as a result of heat-shock response and impaired interferon- $\gamma$ licensing. Cytotherapy 14, 147-152. doi: 10.3109/14653249.2011. 623691

Gad, E. S., Salama, A., El-Shafie, M. F., Arafa, H. M. M., Abdelsalam, R. M., and Khattab, M. (2020). The anti-fibrotic and anti-inflammatory potential of bone marrow-derived mesenchymal stem cells and Nintedanib in bleomycininduced lung fibrosis in rats. Inflammation 43, 123-134. doi: 10.1007/s10753019-01101-2

Gallo, G., Tiesi, V., Fulginiti, S., De Paola, G., Vescio, G., and Sammarco, G. (2020). Mesenchymal stromal cell therapy in the management of perianal fistulas in Crohn's disease: an up-to-date review. Medicina (Kaunas) 56:563. doi: 10.3390/ medicina56110563
George, P. M., Patterson, C. M., Reed, A. K., and Thillai, M. (2019). Lung transplantation for idiopathic pulmonary fibrosis. Lancet Respir. Med. 7, 271282. doi: 10.1016/S2213-2600(18)30502-2

Glassberg, M. K., Minkiewicz, J., Toonkel, R. L., Simonet, E. S., Rubio, G. A., Difede, D., et al. (2017). Allogeneic human mesenchymal stem cells in patients with idiopathic pulmonary fibrosis via intravenous delivery (AETHER): a phase i safety clinical trial. Chest 151, 971-981. doi: 10.1016/j.chest.2016.10.061

Gordon, S., Plüddemann, A., and Martinez Estrada, F. (2014). Macrophage heterogeneity in tissues: phenotypic diversity and functions. Immunol. Rev. 262, 36-55. doi: 10.1111/imr.12223

Grimminger, F., Günther, A., and Vancheri, C. (2015). The role of tyrosine kinases in the pathogenesis of idiopathic pulmonary fibrosis. Eur. Respir. J. 45, 1426-1433. doi: 10.1183/09031936.00149614

Hare, J. M., Difede, D. L., Rieger, A. C., Florea, V., Landin, A. M., El-Khorazaty, J., et al. (2017). Randomized comparison of allogeneic versus autologous mesenchymal stem cells for nonischemic dilated cardiomyopathy: POSEIDONDCM trial. J. Am. Coll. Cardiol. 69, 526-537. doi: 10.1016/j.jacc.2016.11.009

Harrell, C. R., Markovic, B. S., Fellabaum, C., Arsenijevic, N., Djonov, V., and Volarevic, V. (2020). The role of Interleukin 1 receptor antagonist in mesenchymal stem cell-based tissue repair and regeneration. Biofactors 46, 263-275. doi: 10.1002/biof.1587

He, F., Wang, Y., Li, Y., and Yu, L. (2020). Human amniotic mesenchymal stem cells alleviate paraquat-induced pulmonary fibrosis in rats by inhibiting the inflammatory response. Life Sci. 243:117290. doi: 10.1016/j.lfs.2020.117290

Hong, Y., Kim, Y. S., Hong, S. H., and Oh, Y. M. (2016). Therapeutic effects of adipose-derived stem cells pretreated with pioglitazone in an emphysema mouse model. Exp. Mol. Med. 48:e266. doi: 10.1038/emm.2016.93

Huleihel, L., Sellares, J., Cardenes, N., Álvarez, D., Faner, R., Sakamoto, K., et al. (2017). Modified mesenchymal stem cells using miRNA transduction alter lung injury in a bleomycin model. Am. J. Physiol. Lung Cell. Mol. Physiol. 313, L92-L103. doi: 10.1152/ajplung.00323.2016

Islam, D., Huang, Y., Fanelli, V., Delsedime, L., Wu, S., Khang, J., et al. (2019). Identification and modulation of microenvironment is crucial for effective mesenchymal stromal cell therapy in acute lung injury. Am. J. Respir. Crit. Care Med. 199, 1214-1224. doi: 10.1164/rccm.201802-0356OC

Janowski, M., Lyczek, A., Engels, C., Xu, J., Lukomska, B., Bulte, J. W., et al. (2013). Cell size and velocity of injection are major determinants of the safety of intracarotid stem cell transplantation. J. Cereb. Blood Flow Metab. 33, 921-927. doi: $10.1038 /$ jcbfm.2013.32

Jenkins, R. G., Moore, B. B., Chambers, R. C., Eickelberg, O., Königshoff, M., Kolb, M., et al. (2017). An official american thoracic society workshop report: use of animal models for the preclinical assessment of potential therapies for pulmonary fibrosis. Am. J. Respir. Cell Mol. Biol. 56, 667-679. doi: 10.1165/ rcmb.2017-0096ST

Ji, H. L., Liu, C., and Zhao, R. Z. (2020). Stem cell therapy for COVID-19 and other respiratory diseases: global trends of clinical trials. World J. Stem Cells 12, 471-480. doi: 10.4252/wjsc.v12.i6.471

Jun, D., Garat, C., West, J., Thorn, N., Chow, K., Cleaver, T., et al. (2011). The pathology of bleomycin-induced fibrosis is associated with loss of resident lung mesenchymal stem cells that regulate effector T-cell proliferation. Stem Cells 29, 725-735. doi: 10.1002/stem.604

Kabat, M., Bobkov, I., Kumar, S., and Grumet, M. (2020). Trends in mesenchymal stem cell clinical trials 2004-2018: is efficacy optimal in a narrow dose range? Stem Cells Transl. Med. 9, 17-27. doi: 10.1002/sctm.19-0202

Karampitsakos, T., Tzilas, V., Tringidou, R., Steiropoulos, P., Aidinis, V., Papiris, S. A., et al. (2017). Lung cancer in patients with idiopathic pulmonary fibrosis. Pulm. Pharmacol. Ther. 45, 1-10. doi: 10.1016/j.pupt.2017.03.016

Kardia, E., Ch'ng, E. S., and Yahaya, B. H. (2018). Aerosol-based airway epithelial cell delivery improves airway regeneration and repair. J. Tissue Eng. Regen. Med. 12, e995-e1007. doi: 10.1002/term.2421

Kean, T. J., Lin, P., Caplan, A. I., and Dennis, J. E. (2013). MSCs: delivery routes and engraftment, cell-targeting strategies, and immune modulation. Stem Cells Int. 2013:732742. doi: 10.1155/2013/732742

Kern, S., Eichler, H., Stoeve, J., Klüter, H., and Bieback, K. (2006). Comparative analysis of mesenchymal stem cells from bone marrow, umbilical cord blood, or adipose tissue. Stem Cells 24, 1294-1301. doi: 10.1634/stemcells.20050342

Khatri, M., Richardson, L. A., and Meulia, T. (2018). Mesenchymal stem cellderived extracellular vesicles attenuate influenza virus-induced acute lung 
injury in a pig model. Stem Cell Res. Ther. 9:17. doi: 10.1186/s13287-0180774-8

Kim, K. K., Sheppard, D., and Chapman, H. A. (2018). TGF- $\beta 1$ signaling and tissue fibrosis. Cold Spring Harb. Perspect. Biol. 10:a022293. doi: 10.1101/cshperspect. a022293

Kim, S. Y., Burgess, J. K., Wang, Y., Kable, E. P., Weiss, D. J., Chan, H. K., et al. (2016). Atomized human amniotic mesenchymal stromal cells for direct delivery to the airway for treatment of lung injury. J. Aerosol. Med. Pulm. Drug Deliv. 29, 514-524. doi: 10.1089/jamp.2016.1289

Kitoko, J. Z., De Castro, L. L., Nascimento, A. P., Abreu, S. C., Cruz, F. F., Arantes, A. C., et al. (2018). Therapeutic administration of bone marrowderived mesenchymal stromal cells reduces airway inflammation without upregulating Tregs in experimental asthma. Clin. Exp. Allergy 48, 205-216. doi: 10.1111/cea.13048

Lan, Y. W., Choo, K. B., Chen, C. M., Hung, T. H., Chen, Y. B., Hsieh, C. H., et al. (2015). Hypoxia-preconditioned mesenchymal stem cells attenuate bleomycininduced pulmonary fibrosis. Stem Cell Res. Ther. 6:97. doi: 10.1186/s13287015-0081-6

Lan, Y. W., Theng, S. M., Huang, T. T., Choo, K. B., Chen, C. M., Kuo, H. P., et al. (2017). Oncostatin M-preconditioned mesenchymal stem cells alleviate bleomycin-induced pulmonary fibrosis through paracrine effects of the hepatocyte growth factor. Stem Cells Transl. Med. 6, 1006-1017. doi: 10.5966/ sctm.2016-0054

Lawson, W. E., Cheng, D. S., Degryse, A. L., Tanjore, H., Polosukhin, V. V., Xu, X. C., et al. (2011). Endoplasmic reticulum stress enhances fibrotic remodeling in the lungs. Proc. Natl. Acad. Sci. U.S.A. 108, 10562-10567. doi: 10.1073/pnas. 1107559108

Lazarus, H. M., Haynesworth, S. E., Gerson, S. L., Rosenthal, N. S., and Caplan, A. I. (1995). Ex vivo expansion and subsequent infusion of human bone marrowderived stromal progenitor cells (mesenchymal progenitor cells): implications for therapeutic use. Bone Marrow Transplant. 16, 557-564.

Lederer, D. J., and Martinez, F. J. (2018). Idiopathic pulmonary fibrosis. N. Engl. J. Med. 378, 1811-1823. doi: 10.1056/NEJMra1705751

Leibacher, J., and Henschler, R. (2016). Biodistribution, migration and homing of systemically applied mesenchymal stem/stromal cells. Stem Cell Res. Ther. 7:7. doi: 10.1186/s13287-015-0271-2

Li, B., Li, C., Zhu, M., Zhang, Y., Du, J., Xu, Y., et al. (2017a). Hypoxia-induced mesenchymal stromal cells exhibit an enhanced therapeutic effect on radiationinduced lung injury in mice due to an increased proliferation potential and enhanced antioxidant ability. Cell. Physiol. Biochem. 44, 1295-1310. doi: 10. $1159 / 000485490$

Li, F., Han, F., Li, H., Zhang, J., Qiao, X., Shi, J., et al. (2017b). Human placental mesenchymal stem cells of fetal origins-alleviated inflammation and fibrosis by attenuating MyD88 signaling in bleomycin-induced pulmonary fibrosis mice. Mol. Immunol. 90, 11-21. doi: 10.1016/j.molimm.2017.06.032

Li, X., An, G., Wang, Y., Liang, D., Zhu, Z., Lian, X., et al. (2017c). Anti-fibrotic effects of bone morphogenetic protein-7-modified bone marrow mesenchymal stem cells on silica-induced pulmonary fibrosis. Exp. Mol. Pathol. 102, 70-77. doi: 10.1016/j.yexmp.2016.12.010

Li, X., Wang, Y., An, G., Liang, D., Zhu, Z., Lian, X., et al. (2017d). Bone marrow mesenchymal stem cells attenuate silica-induced pulmonary fibrosis via paracrine mechanisms. Toxicol. Lett. 270, 96-107. doi: 10.1016/j.toxlet. 2017.02.016

Liao, L., Shi, B., Chang, H., Su, X., Zhang, L., Bi, C., et al. (2017). Heparin improves BMSC cell therapy: anticoagulant treatment by heparin improves the safety and therapeutic effect of bone marrow-derived mesenchymal stem cell cytotherapy. Theranostics 7, 106-116. doi: 10.7150/thno.16911

Liu, D., Kong, F., Yuan, Y., Seth, P., Xu, W., Wang, H., et al. (2018). Decorinmodified umbilical cord mesenchymal stem cells (MSCs) attenuate radiationinduced lung injuries via regulating inflammation, fibrotic factors, and immune responses. Int. J. Radiat. Oncol. Biol. Phys. 101, 945-956. doi: 10.1016/j.ijrobp. 2018.04.007

Liu, W. W., Wang, H. X., Yu, W., Bi, X. Y., Chen, J. Y., Chen, L. Z., et al. (2015). Treatment of silicosis with hepatocyte growth factor-modified autologous bone marrow stromal cells: a non-randomized study with follow-up. Genet. Mol. Res. 14, 10672-10681. doi: 10.4238/2015.September.9.7

Liu, Y. Y., Chiang, C. H., Hung, S. C., Chian, C. F., Tsai, C. L., Chen, W. C., et al. (2017). Hypoxia-preconditioned mesenchymal stem cells ameliorate ischemia/reperfusion-induced lung injury. PLoS One 12:e0187637. doi: 10. 1371/journal.pone.0187637
Lu, Q., and El-Hashash, A. H. K. (2019). Cell-based therapy for idiopathic pulmonary fibrosis. Stem Cell Investig. 6:22. doi: 10.21037/sci.2019.06.09

Luo, X. Y., Meng, X. J., Cao, D. C., Wang, W., Zhou, K., Li, L., et al. (2019). Transplantation of bone marrow mesenchymal stromal cells attenuates liver fibrosis in mice by regulating macrophage subtypes. Stem Cell Res. Ther. 10:16. doi: 10.1186/s13287-018-1122-8

Martinez, F. J., and Flaherty, K. R. (2017). Comprehensive and individualized patient care in idiopathic pulmonary fibrosis: refining approaches to diagnosis, prognosis, and treatment. Chest 151, 1173-1174. doi: 10.1016/j.chest.2017.03.017

McCarthy, S. D., Horgan, E., Ali, A., Masterson, C., Laffey, J. G., Macloughlin, R., et al. (2020). Nebulized mesenchymal stem cell derived conditioned medium retains antibacterial properties against clinical pathogen isolates. J. Aerosol Med. Pulm. Drug Deliv. 33, 140-152. doi: 10.1089/jamp.2019.1542

Min, F., Gao, F., Li, Q., and Liu, Z. (2015). Therapeutic effect of human umbilical cord mesenchymal stem cells modified by angiotensin-converting enzyme 2 gene on bleomycin-induced lung fibrosis injury. Mol. Med. Rep. 11, 2387-2396. doi: $10.3892 / \mathrm{mmr} .2014 .3025$

Morimoto, Y., Hirahara, K., Kiuchi, M., Wada, T., Ichikawa, T., Kanno, T., et al. (2018). Amphiregulin-producing pathogenic memory t helper 2 cells instruct eosinophils to secrete osteopontin and facilitate airway fibrosis. Immunity 49, 134.e-150.e. doi: 10.1016/j.immuni.2018.04.023

Moroncini, G., Paolini, C., Orlando, F., Capelli, C., Grieco, A., Tonnini, C., et al. (2018). Mesenchymal stromal cells from human umbilical cord prevent the development of lung fibrosis in immunocompetent mice. PLoS One 13:e0196048. doi: 10.1371/journal.pone.0196048

Morrison, T. J., Jackson, M. V., Cunningham, E. K., Kissenpfennig, A., Mcauley, D. F., O'kane, C. M., et al. (2017). Mesenchymal stromal cells modulate macrophages in clinically relevant lung injury models by extracellular vesicle mitochondrial transfer. Am. J. Respir. Crit. Care Med. 196, 1275-1286. doi: 10.1164/rccm.201701-0170OC

Naikawadi, R. P., Disayabutr, S., Mallavia, B., Donne, M. L., Green, G., La, J. L., et al. (2016). Telomere dysfunction in alveolar epithelial cells causes lung remodeling and fibrosis. JCI Insight 1:e86704. doi: 10.1172/jci.insight.86704

Najar, M., Bouhtit, F., Melki, R., Afif, H., Hamal, A., Fahmi, H., et al. (2019). Mesenchymal stromal cell-based therapy: new perspectives and challenges. J. Clin. Med. 8:626. doi: 10.3390/jcm8050626

Ni, K., Liu, M., Zheng, J., Wen, L., Chen, Q., Xiang, Z., et al. (2018). PD-1/PD-L1 pathway mediates the alleviation of pulmonary fibrosis by human mesenchymal stem cells in humanized mice. Am. J. Respir. Cell Mol. Biol. 58, 684-695. doi: 10.1165/rcmb.2017-0326OC

Nitzsche, F., Müller, C., Lukomska, B., Jolkkonen, J., Deten, A., and Boltze, J. (2017). Concise review: MSC adhesion cascade-insights into homing and transendothelial migration. Stem Cells 35, 1446-1460. doi: 10.1002/stem. 2614

Ntolios, P., Manoloudi, E., Tzouvelekis, A., Bouros, E., Steiropoulos, P., Anevlavis, S., et al. (2018). Longitudinal outcomes of patients enrolled in a phase Ib clinical trial of the adipose-derived stromal cells-stromal vascular fraction in idiopathic pulmonary fibrosis. Clin. Respir. J. 12, 2084-2089. doi: 10.1111/crj.12777

Oggu, G. S., Sasikumar, S., Reddy, N., Ella, K. K. R., Rao, C. M., and Bokara, K. K. (2017). Gene delivery approaches for mesenchymal stem cell therapy: strategies to increase efficiency and specificity. Stem Cell Rev. Rep. 13, 725-740. doi: 10.1007/s12015-017-9760-2

Paliwal, S., Chaudhuri, R., Agrawal, A., and Mohanty, S. (2018). Regenerative abilities of mesenchymal stem cells through mitochondrial transfer. J. Biomed. Sci. 25:31. doi: 10.1186/s12929-018-0429-1

Periera-Simon, S., Xia, X., Catanuto, P., Coronado, R., Kurtzberg, J., Bellio, M., et al. (2021). Anti-fibrotic effects of different sources of MSC in bleomycininduced lung fibrosis in C57BL6 male mice. Respirology 26, 161-170. doi: $10.1111 /$ resp. 13928

Petrenko, Y., Vackova, I., Kekulova, K., Chudickova, M., Koci, Z., Turnovcova, K., et al. (2020). A comparative analysis of multipotent mesenchymal stromal cells derived from different sources, with a focus on neuroregenerative potential. Sci. Rep. 10:4290. doi: 10.1038/s41598-020-61167-z

Poggio, H. A., Antunes, M. A., Rocha, N. N., Kitoko, J. Z., Morales, M. M., Olsen, P. C., et al. (2018). Impact of one versus two doses of mesenchymal stromal cells on lung and cardiovascular repair in experimental emphysema. Stem Cell Res. Ther. 9:296. doi: 10.1186/s13287-018-1043-6

Raghu, G., Remy-Jardin, M., Myers, J. L., Richeldi, L., Ryerson, C. J., Lederer, D. J., et al. (2018). Diagnosis of idiopathic pulmonary fibrosis. an official 
ATS/ERS/JRS/ALAT clinical practice guideline. Am. J. Respir. Crit. Care Med. 198, e44-e68.

Reddy, M., Fonseca, L., Gowda, S., Chougule, B., Hari, A., and Totey, S. (2016). Human adipose-derived mesenchymal stem cells attenuate early stage of bleomycin induced pulmonary fibrosis: comparison with pirfenidone. Int. J. Stem Cells 9, 192-206. doi: 10.15283/ijsc16041

Richeldi, L., Kreuter, M., Selman, M., Crestani, B., Kirsten, A. M., Wuyts, W. A., et al. (2018). Long-term treatment of patients with idiopathic pulmonary fibrosis with nintedanib: results from the TOMORROW trial and its open-label extension. Thorax 73, 581-583. doi: 10.1136/thoraxjnl-2016-209701

Rubio, G. A., Elliot, S. J., Wikramanayake, T. C., Xia, X., Pereira-Simon, S., Thaller, S. R., et al. (2018). Mesenchymal stromal cells prevent bleomycin-induced lung and skin fibrosis in aged mice and restore wound healing. J. Cell. Physiol. 233, 5503-5512. doi: 10.1002/jcp.26418

Salazar, K. D., Lankford, S. M., and Brody, A. R. (2009). Mesenchymal stem cells produce Wnt isoforms and TGF-betal that mediate proliferation and procollagen expression by lung fibroblasts. Am. J. Physiol. Lung Cell. Mol. Physiol. 297, L1002-L1011. doi: 10.1152/ajplung.90347.2008

Samsonraj, R. M., Raghunath, M., Nurcombe, V., Hui, J. H., Van Wijnen, A. J., and Cool, S. M. (2017). Concise review: multifaceted characterization of human mesenchymal stem cells for use in regenerative medicine. Stem Cells Transl. Med. 6, 2173-2185. doi: 10.1002/sctm.17-0129

Schlosser, K., Wang, J. P., Dos Santos, C., Walley, K. R., Marshall, J., Fergusson, D. A., et al. (2019). Effects of mesenchymal stem cell treatment on systemic cytokine levels in a phase 1 dose escalation safety trial of septic shock patients. Crit. Care Med. 47, 918-925. doi: 10.1097/CCM.0000000000003657

Sensebé, L., Tarte, K., Galipeau, J., Krampera, M., Martin, I., Phinney, D. G., et al. (2012). Limited acquisition of chromosomal aberrations in human adult mesenchymal stromal cells. Cell Stem Cell 10, 9-10; author reply 10-11. doi: 10.1016/j.stem.2011.12.005

Serrano-Mollar, A. (2018). Cell therapy in idiopathic pulmonary fibrosis( $\dagger$ ). Med. Sci. (Basel) 6:64. doi: 10.3390/medsci6030064

Sgalla, G., Iovene, B., Calvello, M., Ori, M., Varone, F., and Richeldi, L. (2018). Idiopathic pulmonary fibrosis: pathogenesis and management. Respir. Res. 19:32. doi: 10.1186/s12931-018-0730-2

Shenderov, K., Collins, S. L., Powell, J. D., and Horton, M. R. (2021). Immune dysregulation as a driver of idiopathic pulmonary fibrosis. J. Clin. Invest. 131:e143226. doi: 10.1172/JCI143226

Shirjang, S., Mansoori, B., Solali, S., Hagh, M. F., and Shamsasenjan, K. (2017). Toll-like receptors as a key regulator of mesenchymal stem cell function: an up-to-date review. Cell. Immunol. 315, 1-10. doi: 10.1016/j.cellimm.2016. 12.005

Siegel, G., Kluba, T., Hermanutz-Klein, U., Bieback, K., Northoff, H., and Schäfer, R. (2013). Phenotype, donor age and gender affect function of human bone marrow-derived mesenchymal stromal cells. BMC Med 11:146. doi: 10.1186/ 1741-7015-11-146

Silva, L. H. A., Antunes, M. A., Dos Santos, C. C., Weiss, D. J., Cruz, F. F., and Rocco, P. R. M. (2018). Strategies to improve the therapeutic effects of mesenchymal stromal cells in respiratory diseases. Stem Cell Res. Ther. 9:45. doi: 10.1186/s13287-018-0802-8

Sun, C., Wang, L., Wang, H., Huang, T., Yao, W., Li, J., et al. (2020). Singlecell RNA-seq highlights heterogeneity in human primary Wharton's jelly mesenchymal stem/stromal cells cultured in vitro. Stem Cell Res. Ther. 11:149. doi: 10.1186/s13287-020-01660-4

Tashiro, J., Elliot, S. J., Gerth, D. J., Xia, X., Pereira-Simon, S., Choi, R., et al. (2015). Therapeutic benefits of young, but not old, adipose-derived mesenchymal stem cells in a chronic mouse model of bleomycin-induced pulmonary fibrosis. Transl. Res. 166, 554-567. doi: 10.1016/j.trsl.2015.09.004

Tibboel, J., Keijzer, R., Reiss, I., De Jongste, J. C., and Post, M. (2014). Intravenous and intratracheal mesenchymal stromal cell injection in a mouse model of pulmonary emphysema. COPD 11, 310-318. doi: 10.3109/15412555.2013. 854322

Torre, M. L., Lucarelli, E., Guidi, S., Ferrari, M., Alessandri, G., De Girolamo, L., et al. (2015). Ex vivo expanded mesenchymal stromal cell minimal quality requirements for clinical application. Stem Cells Dev. 24, 677-685. doi: 10.1089/ scd.2014.0299

Tzouvelekis, A., Bonella, F., and Spagnolo, P. (2015). Update on therapeutic management of idiopathic pulmonary fibrosis. Ther. Clin. Risk Manag. 11, 359-370. doi: 10.2147/TCRM.S69716
Tzouvelekis, A., Paspaliaris, V., Koliakos, G., Ntolios, P., Bouros, E., Oikonomou, A., et al. (2013). A prospective, non-randomized, no placebo-controlled, phase Ib clinical trial to study the safety of the adipose derived stromal cells-stromal vascular fraction in idiopathic pulmonary fibrosis. J. Transl. Med. 11:171. doi: 10.1186/1479-5876-11-171

Wang, N., Zhao, T. T., Li, S. M., Li, Y. H., Wang, Y. J., Li, D. S., et al. (2019). Fibroblast growth factor 21 ameliorates pancreatic fibrogenesis via regulating polarization of macrophages. Exp. Cell Res. 382:111457. doi: 10.1016/j.yexcr. 2019.06.002

Wang, Q., Zhu, H., Zhou, W. G., Guo, X. C., Wu, M. J., Xu, Z. Y., et al. (2013). N-acetylcysteine-pretreated human embryonic mesenchymal stem cell administration protects against bleomycin-induced lung injury. Am. J. Med. Sci. 346, 113-122. doi: 10.1097/MAJ.0b013e318266e8d8

Wang, W., and Han, Z. C. (2019). Heterogeneity of human mesenchymal stromal/stem cells. Adv. Exp. Med. Biol. 1123, 165-177. doi: 10.1007/978-3030-11096-3_10

Waszak, P., Alphonse, R., Vadivel, A., Ionescu, L., Eaton, F., and Thébaud, B. (2012). Preconditioning enhances the paracrine effect of mesenchymal stem cells in preventing oxygen-induced neonatal lung injury in rats. Stem Cells Dev. 21, 2789-2797. doi: 10.1089/scd.2010.0566

Willis, G. R., Fernandez-Gonzalez, A., Anastas, J., Vitali, S. H., Liu, X., Ericsson, M., et al. (2018). Mesenchymal stromal cell exosomes ameliorate experimental bronchopulmonary dysplasia and restore lung function through macrophage immunomodulation. Am. J. Respir. Crit. Care Med. 197, 104-116. doi: 10.1164/ rccm.201705-0925OC

Wu, J., Song, D., Li, Z., Guo, B., Xiao, Y., Liu, W., et al. (2020). Immunity-andmatrix-regulatory cells derived from human embryonic stem cells safely and effectively treat mouse lung injury and fibrosis. Cell Res. 30, 794-809. doi: 10.1038/s41422-020-0354- 1

Xu, L., Ding, L., Wang, L., Cao, Y., Zhu, H., Lu, J., et al. (2017). Umbilical cordderived mesenchymal stem cells on scaffolds facilitate collagen degradation via upregulation of MMP-9 in rat uterine scars. Stem Cell Res. Ther. 8:84. doi: 10.1186/s13287-017-0535-0

Yang, G., Zhu, Z., Wang, Y., Gao, A., Niu, P., Chen, L., et al. (2016). Bone morphogenetic protein 7 attenuates epithelial-mesenchymal transition induced by silica. Hum. Exp. Toxicol. 35, 69-77. doi: 10.1177/0960327115577550

Yang, Y. K. (2018). Aging of mesenchymal stem cells: implication in regenerative medicine. Regen. Ther. 9, 120-122. doi: 10.1016/j.reth.2018.09.002

Yao, L., Liu, C. J., Luo, Q., Gong, M., Chen, J., Wang, L. J., et al. (2013). Protection against hyperoxia-induced lung fibrosis by KGF-induced MSCs mobilization in neonatal rats. Pediatr. Transplant. 17, 676-682. doi: 10.1111/petr.12133

Zhang, E., Yang, Y., Chen, S., Peng, C., Lavin, M. F., Yeo, A. J., et al. (2018). Bone marrow mesenchymal stromal cells attenuate silica-induced pulmonary fibrosis potentially by attenuating Wnt/ $\beta$-catenin signaling in rats. Stem Cell Res. Ther. 9:311. doi: 10.1186/s13287-018-1045-4

Zhang, X., Wang, H., Shi, Y., Peng, W., Zhang, S., Zhang, W., et al. (2012). Role of bone marrow-derived mesenchymal stem cells in the prevention of hyperoxia-induced lung injury in newborn mice. Cell Biol. Int. 36, 589-594. doi: 10.1042/CBI20110447

Zhang, Y., Jiang, X., and Ren, L. (2019). Optimization of the adipose-derived mesenchymal stem cell delivery time for radiation-induced lung fibrosis treatment in rats. Sci. Rep. 9:5589. doi: 10.1038/s41598-019-41576-5

Zhao, F., Liu, W., Yue, S., Yang, L., Hua, Q., Zhou, Y., et al. (2019). Pretreatment with G-CSF could enhance the antifibrotic effect of BM-MSCs on pulmonary fibrosis. Stem Cells Int. 2019:1726743. doi: 10.1155/2019/1726743

Zhao, R., Su, Z., Wu, J., and Ji, H. L. (2017). Serious adverse events of cell therapy for respiratory diseases: a systematic review and meta-analysis. Oncotarget 8, 30511-30523. doi: 10.18632/oncotarget.15426

Conflict of Interest: The authors declare that the research was conducted in the absence of any commercial or financial relationships that could be construed as a potential conflict of interest.

Copyright (C) 2021 Yang, Liu, Jiang, Wang, Dai and Wang. This is an open-access article distributed under the terms of the Creative Commons Attribution License (CC BY). The use, distribution or reproduction in other forums is permitted, provided the original author(s) and the copyright owner(s) are credited and that the original publication in this journal is cited, in accordance with accepted academic practice. No use, distribution or reproduction is permitted which does not comply with these terms. 